\title{
LA INTERPRETACIÓN DE LAS CLAVES BUCÓLICAS EN LA POESÍA RENACENTISTA
}

\author{
Ramón Mateo Mateo \\ Profesor tutor de la UNED-Vergara
}

\section{LA lectura del TEXTO Pó́tico Como Clave}

En el campo de los estudios garcilasianos algunos críticos han apuntado en los últimos tiempos la conveniencia de revisar, matizar o corregir la interpretación autobiographico modo de ciertos pasajes, y de modo muy especial de la Égloga $I^{1}$. Luis Iglesias Feijoo propone al respecto «leer los poemas como lo que son: perfectos y complejos organismos literarios que hablan por sí mismos, sin necesidad de acudir para entenderlos a claves

Cfr. David QuINN, «Garcilaso's Égloga primera: Autobiography or Art?», Symposium, XXXVII (1983), pp. 147-164; Adrien RolG, «Quiénes fueron Salicio y Nemoroso?», Criticón, 4 (1978), pp. 1-36. Contra el mito de Isabel Freire se han levantado diversas voces: Frank Goodwyn, «New Light on the Historical Setting of Garcilaso's Poetry», Hispanic Review, XLVI (1978), pp. 1-22; David H. DARST, «Garcilaso's Love for Isabel Freire: The Creation of a Myth", Journal of Hispanic Philology, III (1979), pp. 261-268; Pamela WALEY, "Garcilaso, Isabel and Elena: The growth of a legend", Bulletin of Hispanic Studies, LVI (1979), pp. 1115. Al hilo de las objeciones expuestas por algunos de estos críticos, Carrol B. Johnson se ha planteado la cuestión de quién podría estar detrás de la poesía amorosa de Garcilaso si no lo fuera Isabel Freire, analizando para ello tres poemas: el soneto X, la Ode ad Florem Gnidi y la Eg. III (cfr. «Personal Involvement and Poetic Tradition in the Spanish Renaissance: Some Thoughts on Reading Garcilaso", Romanic Review, LXXX [1989]. pp. 288-304). En un artículo próximo ofreceremos un resumen de la incidencia del procedimiento alusivo en los textos bucólicos del siglo XVI. 
externas $»^{2}$, A nosotros nos parece, sin embargo, que sigue siendo válida esa lectura de Garcilaso. No se trata, desde luego, de perseverar en una crítica histórico-biográfica de corte decimonónico para construir con los versos la biografia del poeta, sino de leerlos ayudados por esa biografia. Que toda obra poética tiene un significado en sí misma es algo bien sabido desde que en la segunda década de nuestro siglo comenzaron a definirse los principios de un inmanentismo crítico que perdura hasta hoy; pero no menos evidente es que el conocimiento de las circunstancias (personales, sociales, contextuales e intertextuales) en que se escribió nos proporcionará un mejor entendimiento de su total sentido ${ }^{3}$.

Este asunto debe considerarse, además, a la luz de la particular naturaleza del género literario en que tal clase de poesía se inserta. Y no habrá que olvidar, precisamente, que la realidad contemporánea (más o menos personal) incide de modo innegable en la tradición de la poesía pastoril. Garcilaso conocía bien, cuando eligió la fórmula bucólica, lo que el género tenía de poesía de ocasión. Su genialidad estuvo en haber aprovechado el espíritu arcádico y aquella capacidad de aplicarse a la referencia personal concreta sin despojar por ello a su poesía de «la carga infinita de la belleza» ${ }^{4}$. Si nos fuera permitido aplicar la conocida y sabia definición machadiana de la poesía como «la palabra esencial en el tiempo», diríamos que la temporalidad de Garcilaso que se nos da en el contenido de sus intuiciones, o sea, de los sentimientos vividos, no resta esencialidad a su palabra poética porque venga expresada en el contexto de esa historia personal. Y la eventualidad de que un día pueda descubrirse «que la novela amorosa con Isabel Freire es una bella invención" y que con ello "se nos deshaga entre las manos el encanto de unos poemas que no habrán variado" ${ }^{5}$, nos parece absolutamente improbable; porque, al margen de la persona concreta - si no fue la bella portuguesa la inspiradora, otra habría de serlo $^{6}-$, el estímulo creador fue siempre de esta clase para aquellos poetas.

2 «Lectura de la Egloga I», Academia Literaria Renacentista. IV: Garcilaso, Salamanca, 1986, 61-82, p. 66. También José LARA GARRIDo ha advertido del riesgo que entraña -por las múltiples interferencias onomásticas - esta lectura («Sobre la validez de las claves bucólicas (Examen de algunos ejemplos)», Analecta Malacitana, IV [1981], pp. 393-400).

${ }^{3}$ Con el mismo razonamiento resuelve Lapesa la cuestión que tratamos: «Es indiscutible -casi perogrullesco- que toda obra poética nos interesa, ante todo y sobre todo, por sí misma, independientemente de las circunstancias en que su autor la cré. No menos cierto es que el conocimiento de tales circunstancias contribuye a la comprensión del poema, tanto en lo que se refiere a sus móviles y sentido cuanto en lo que atañe al proceso creador, al modo peculiar de transformar el poeta sus vivencias y mundo circundante hasta convertir uno y otras en entidades poéticas [...])" (Garcilaso: Estudios completos, Madrid, Istmo, 1984, p. 199).

- Son palabras de Juan Ramón Jiménez que cita Iglesias Feisoo, op. cit., p. 67.

Ibidem, p. 66

- La experiencia puede ser también imaginada, como así sucedió con no pocos poetas; y habrá de considerarse como experiencia vivida poéticamente. Una postura bastante similar 
Pero plantear el problema de tal modo implica hacer gravitar la obra sobre la vigencia de esa ecuación, lo que distorsiona, sin duda, la esencia de la composición. Nadie pretenderá defender hoy una interpretación semejante de las claves bucólicas, pues por importante que haya sido dicha equivalencia en la génesis de estas piezas, la referencia personal acaba teniendo una importancia secundaria. En ellas, anota F. López Estrada, «la verdad universal de la poesía, que es perdurable, se sobrepone a la anécdota del origen" ${ }^{7}$, pronto olvidada por los lectores. Aunque, al no ser ya ésta una clase de poesía de lectura que podríamos llamar de "consumo», sino producto cultural que se ofrece con valor «arqueológico» a un público que ha de ser convenientemente adaptado a la circunstancia histórica, convendrá no perder nunca de vista ni su modo de composición ni el de la recepción ${ }^{8}$. En estas páginas nos proponemos poner de relieve la importancia en origen del fenómeno alusivo en el género bucólico, como dato necesario para una lectura suficiente de los textos poéticos.

\section{AMOR Y OCULTAMIENTO}

El uso (y abuso) de la onomástica bucólica ${ }^{9}$ transciende los límites de un género que tanta fascinación ejerció sobre el mundo renacentista y se acepta con carácter universal en la comunicación literaria de la experiencia (real o imaginaria) del amor. Todos los autores se visten con el pellico pas-

adopta S. Zimic respecto de la eventualidad indicada: "Aun de destacarse como improbable o irreal la relación específica de Garcilaso e Isabel Freire con los personajes de la obra [se refiere en particular a la Eg. I], se podria sustentar licitamente el carácter autobiográfico de ésta sólo a base de la asimilación patente del yo del poeta con el de Salicio y Nemoroso. Cuando menos, se podria hablar de una obra ficticiamente autobiográfica, lo cual abriría nuevas fascinantes posibilidades de interpretación» («Las églogas de Garcilaso de la Vega: ensayos de interpretación», Boletín de la Biblioteca Menéndez Pelayo, LXIV [1988], 5-107, p. 33, nota 57$)$.

7 Los libros de pastores en la literatura española (La órbita previa), Madrid, Gredos, 1974, p. 488.

${ }^{8}$ «La Historia literaria - dice A. García Berrio-controla y ajusta por tanto la recepción de los textos artisticos. Su objetivo más general desde este punto de vista es que cada nueva promoción de lectores descubra, sin el entorpecimiento del conjunto social e histórico de valencias significativas de su propia época, el sistema de significados que motivaron en su aparición el mensaje de la obra y su significado en la intención del autor, tanto el general histórico y conceptual, como el estético" (Teoría de la Literatura, Madrid, Cátedra, 1989, p. 45).

${ }^{9}$ Para el renacentista, dice F. Rigolot, el nombre poético es un autógrafo descifrable (Póetique et onomastique. L'exemple de la Renaissance, Genève, Librairie Droz, 1977, p. 229). Nunca como entonces, dice, se ha meditado tanto acerca del poder de los nombres (p. 14); la onomástica literaria hace del nombre propio, signo opaco, un signo «remotivado" (p. 12). 
toril para expresar las incidencias del proceso de sus amores. Bien lo muestra el enfado de Leonardo de Argensola por tal profusión de seudónimos, y en particular por los popularizados por los romances juveniles de Lope de Vega:

Hoy estuvimos yo y el Nuncio juntos, y tratamos de algunas parlerías, echando cantollano y contrapuntos.

Mas no se han de contar como poesias, pues no eres Filis tú, ni yo Belardo, enfado general de nuestros dias ${ }^{10}$.

El sobrenombre de sabor bucólico conoció, en efecto, una difusión amplia por contextos bien ajenos a la ficción originaria: la pastoralización del nombre confería una peculiar impronta idealizadora a la experiencia personal, a la vez que proporcionaba envoltura adecuada a una expresión más libre de los sentimientos. En un tiempo en que la referencia autobiográfica de la intimidad se manifestaba en modos formularios y conceptuosos, "el fervor pastoril renacentista sirvió - señala Entrambasaguas - para que, bajo nombres eglógicos, los poetas se ocultaran, dejando en los personajes que les servían de disfraz muchos rasgos de su fisonomía que el pudor les obligaba a silenciar o no se atrevían a hacer públicos»". En un «acto de auto-bautismo" ${ }^{12}$, todos los poetas adoptan su seudónimo pastoril y se comunican también los respectivos pormenores amorosos, con la convención bucólica comúnmente aceptada como marco de referencia. $Y$ aun sin llegar a recrear el mundo de la égloga por completo, el empleo del lenguaje propio de ésta adquirió enorme vigencia durante la época; porque la "superposición de la persona real y la imaginaria - anota también Entrambasaguas- per-

10 Bartolomé Leonardo de Argensola, Rimas, ed. de José M. Blecua, Madrid, Clásicos Castellanos, 1974, 2 vols., II: Epístola en respuesta a la de Alonso de Ezquerra, [VI], pp. 148150 , v. 58-63. Cejador, tan opuesto como sabemos a este mundo arcádico, veía en la representación de personas reales "una manera de chismografia elegante», donde los pastores, que son verdaderos cortesanos, "lamentan dengosamente los desdenes de las damas pastoras" ( Historia de la lengua y literatura castellana, Madrid, Gredos, 1972 (facsimil de la 2." ed. de 1928), II, p. 165).

" «Estudio preliminar» a su ed. de las Obras de Pedro Láynez, Madrid, CSIC, 1951, 2 vols., l, p. 161 .

${ }_{12}$ Así lo llama Avalle-Arce (La novela pastoril española, Madrid, Istmo, 1974, 2." ed., p. 260). 
mitia una grata penumbra biográfica, no falta de encanto misterioso ciertamentes ${ }^{13}$.

En el caso de la amada, el recubrimiento de su verdadera identidad (y lo significativo es que los nombres sean pastoriles y no caballerescos, como hasta ahora) se veía favorecido por los convencionalismos del «amor callado" de la lírica cortés (la dama era «innombrable») $)^{14}$. La ficción pastoril soslayaba entonces la dificultad, proporcionando un nombre sin desvelar la identidad $^{15}$.

Entrambasaguas juzga, sin embargo, inseguro o inexistente el carácter autobiográfico de estos nombres pastoriles, que «figuran en muchos casos como pura ornamentación poética» y que "en la mayoría [de los casos] los emplean caprichosamente y hasta en algún momento adecuándolos a la medida del verso ${ }^{16}$. Pero es opinión extremosa, $y$, por ello, inexacta ${ }^{17}$. No

${ }^{13}$ Op. cit., loc. cit.

${ }_{14}$ Son numerosas las ocasiones en que los poetas aluden a esta exigencia:

[...] si preguntado

soy lo demás, en lo demás soy mudo.

(Garcilaso, Son. XXVIII: Poesias completas, ed. de E. L. Rivers, Madrid, Castalia, 2." ed., 1972).

Ved cuál estoy, qué extremo es el que sigo:

que llorando mi mal, para contalle,

la causa callo y los efectos digo.

(CETINA, soneto 76: Sonetos y Madrigales completos, ed. de Begoña López Bueno, Madrid, Cátedra, 1981).

${ }^{15}$ En ello se apoyaba Cetina para reclamar ante la dama su derecho a cantar su amor, como medio de desahogo:

De Dórida me quejo; a ella escribo;

Nadie sabe quién es, ni lo sabría.

(Ep. IV, v. 56-57: Obras, ed. de Joaquín Hazañas y la Rúa [Sevilla, 1895], con presentación de Margarita Peña, México, Porrúa, 1977).

is Op. cit., p. 191.

17 Tampoco debe caerse en el polo opuesto, como hace Rodriguez Marin cuando considera la poesía bucólica de Barahona de Soto como literatura totalmente en clave: "Creo equivocada - replica J. Lara Garrido al respecto- esta actitud desde su base: o bien admitimos que estamos ante nombres pastoriles comunes que parten del acervo clásico e italiano en circulación, o la imposibilidad de adscribir las circunstancias relatadas a algún poeta real de todos los que usaron ese nombre inutiliza la clave como elemento de investigación» (op. cit., p. 395). Hay que matizar, no obstante, que el carácter tópico de los nombres no obliga a excluir su valor autobiográfico: la historia de Damón y Galatea en Acuña, por ejemplo, está bien diferenciada de la que, con los mismos personajes, presenta Láynez en su Ég. I; el prestigio de los nombres (por la procedencia y por el significado) justificaba ese uso múltiple. La prevención sobre los riesgos de la interpretación de determinadas claves bucólicas no puede anular 
ha de negarse que las exigencias métricas hayan podido condicionar la elección ${ }^{18}$, o' que en composiciones de cierto aire frívolo la onomástica responda a una actitud lúdica, lo que es fácilmente comprobable, por ejemplo, en una no desdeñable parcela de la producción sonetística del siglo XVI, y aún más del XVII. Pero esto no parece cumplirse en modo alguno en las églogas poéticas, en especial en los nombres de los personajes principales.

Hay siempre aquí, bajo tales nombres, una historia, más o menos diluida, que afirma el género dentro de la experiencia real. Y este componente personal añade razones para desechar los argumentos de quienes juzgan la pastoral como un género espurio, desde la cervantina desmitificación de Berganza hasta la celebrada definición de "puro dilettantismo estético" de Menéndez Pelayo. Así lo declara Avalle-Arce: «La posibilidad - realidadde que el escritor se piense como pastor debe dar el golpe de gracia a la opinión de aquellos que todavía ven lo pastoril como un género falso" ${ }^{19}$. Y lo ponen de manifiesto, dentro de los poemas bucólicos, las referencias a la historia personal del autor ajenas a lo específico de la ficción pastoril. Verdad es que con una tal mezcla de datos rompe el poeta la coherencia interna de la obra; pero queda así patente la interconexión de todos los elementos argumentales y convalidado el autobiografismo global de la composición. En la Ég. I de Acuña, por ejemplo, el Damón entregado al ejercicio de las armas y las letras (v. 100-108) refleja la juventud del propio poeta cuando aún vivía libre de la pasión amorosa (v. 109-110); más adelante (v. 298-318) se hace mención de las campañas de Carlo Quinto por Alemania, a las que acude Damón, junto con gentes de Nápoles, Roma y Lombardía, abandonando «los campos y ribera amada / del Tesín» (v. 305-306) y alejándose así de la hermosa Galatea, «de quien nunca jamás pudo apartarse» (v. 312) ${ }^{20}$. Lo mismo puede decirse de Cetina, soldado en Italia y en diversos países europeos, cuando en la Canción XI nos presenta a su alter ego, Vandalio, en la ribera del Reno (Rhin) aprovechando un alto en la guerra para componer su canto. $O$ cuando, ampliando la ficción pastoril al círculo familiar y de amigos, Francisco de Aldana bucoliza retrospectivamente, en la Ep. a su hermano Cosme [P. XXXV] (v. 72-90) ${ }^{21}$, su vida en Florencia, a orillas del Arno.

la importancia real de aquella general inclinación renacentista por la representación personal mediante la onomástica, aun cuando fuera ésta en ciertos casos sólo ficción poética.

${ }^{18}$ Así, por ejemplo, en el soneto XIV (lib. II) de Francisco DE LA TORRE (Poesia completa, ed. de M.* Luisa Cerrón Puga, Madrid, Cátedra, 1984), la rima de Hola y Iola (v. 6-7); o la de Alcino y bellocino, en el famoso soneto "Svelta mi manso, mayoral estraño", (ed. facsímil de Felipe B. Pedraza Jiménez de las Rimas de Lope de Vega, Aranjuez, Ara Iovis, 1984, Son. CLXXXVIII).

${ }^{19}$ Op. cit., p. 143. 1981.

20 Poesias, ed. de Lorenzo Rubio González, Valladolid, Institución Cultural Simancas,

${ }^{21}$ Poesías castellanas completas, ed. de José Lara Garrido, Madrid, Cátedra, 1985. 
Estas conexiones entre los sucesos reales de la vida del autor y los episodios de la composición hacen que la poesía bucólica se muestre como un género muy afin a la concepción autobiográfica. $R$. Benitez Claros pone el acento en el sentido confesional de toda esa proyección en el texto de las «humanísimas y emocionantes pasiones» de los personajes pastoriles: «ßPor qué son autobiógrafos, o en todo caso heterobiógrafos, los pastores, los místicos y los pícaros? Sin duda porque se hallan definitivamente comprometidos, complicados, inmersos, en la experiencia que reseñan [...] El poeta pastoril no sólo ofrece un paraíso de excepción material y espiritual, sino que se adentra el primero en él y se erige en su primer beneficiario, en su poblador y explorador autobiógrafo, o sitúa allí a sus más preclaros amigos o favorecedores. El ansia de protagonización se cumple en él [...] El autor se "piensa" a sí mismo como protagonista y crea su doble literario, se convierte en sujeto de la acción, de tal forma que habría que establecer entre él y su proyección poética una relación más íntima que la de la paternidad. Es un verdadero gemelo de sí mismo el que actúa sobre los prados»"22.

Antes que nada, será necesario precisar bien el concepto de lo autobiográfico ${ }^{23}$. J. Romera Castillo señala dos condiciones para la existencia del relato ${ }^{24}$ autobiográfico como tal: una es lo que Philippe Lejeune ${ }^{25}$ llama el pacto autobiográfico, es decir, «el asentimiento y la confirmación del lector ante una obra de ser autobiográfica» ${ }^{26}$; la otra, la exigencia de la triple identidad autor-narrador-personaje: «En la autobiografia, uno de los rasgos esenciales es la identidad - no la semejanza, eso sería relato autobiográfico de ficción- entre el autor (aquel que figura en la cubierta del libro), el narrador del relato y el personaje del que se habla» ${ }^{27}$. Ahí queda definida con claridad la diferencia: identidad frente a semejanza. No halla-

22 Visión de la literatura española, Madrid, Rialp, 1963, pp. 106-107.

${ }^{23}$ Carmen Bobes, para quien la forma autobiográfica es un tipo de discurso histórico, no literario, advierte de la exigencia en este caso de una correspondencia rigurosa entre la realidad y el texto: «Si no es un discurso verificable, es decir, si se utiliza el YO y no se sigue la realidad, entonces ese YO es un indice literario, una manipulación que crea un sentido determinado" (Teoria general de la novela, Madrid, Gredos, 1985, p. 240).

${ }^{24} \mathrm{Y}$ la obra bucólica consiste básicamente en el relato de unos amores, tomando el concepto de relato en el sentido que define Romera: «Una modalidad de escritura que da cuenta de unos hechos ya sea en prosa, en verso o en forma teatral [...] Todos poseen una sustancia narrativa en su estructura profunda, aunque cambien los modos de escritura de superficie» («La literatura, signo autobiográfico: El escritor, signo referencial de su escritura», en J. RoMERa CAstillo [coord.], La literatura como signo, Madrid, Playor, 1981, 13-56, p. 29).

${ }^{25}$ Le pacte autobiographique, Paris, Seuil, 1975.

${ }_{26}$ Op. cit., p. 52.

${ }^{27}$ Ibidem, p. 17. 
mos obra pastoril alguna en la que se cumpla esa triple equivalencia, por lo que, dentro de los diferentes modelos que comprende la literatura autorreferencial (autobiografias, relatos autobiográficos de ficción, memorias, epistolarios, diarios), no es posible incluirlo en el primero.

Si no con los dos, autor y personaje, simultáneamente, bien podría verse identificado el narrador de la égloga poética (la diposición narrativa se da en alrededor de los dos tercios de las églogas escritas en la época ${ }^{28}$ ) con cualquiera de los dos. Pero la equivalencia con uno de los personajes no parece ser la vía de los narradores quinientistas, y ello aun contando con el antecedente próximo de Sincero, narrador-protagonista de la Arcadia sannazariana (si cabe hablar aquí de protagonismos, y en particular respecto de un personaje que sólo figura como eje de la acción de dos de los doce episodios). $Y$ tampoco funciona la identificación explicita de narrador y autor, procedimiento, por lo demás, que rompe el hermetismo del mito pastoril, que, como bien indica Avalle-Arce, «no permite intrusiones personales porque existe por fuera del tiempo y del espacion ${ }^{29}$.

Al autor, como tal, le está vedada la entrada en el espacio pastoril, y para acceder a él habrá de dotarse de algún tipo de acreditación de pertenencia a dicho mundo, ya sea por la atribución de un nombre bucólico ya por alguna alusión indirecta. Se comprende bien la poca viabilidad de su acceso por conducto del narrador cuando se considera que eso mismo podría efectuarlo directamente, proyectándose en los personajes. Los términos doble y gemelo reflejan con exactitud la relación entre autor y personaje, pero no dan cuenta de la metamorfosis idealizante experimentada en el proceso. No hay, por tanto, autobiografia en sentido estricto, sino relato autobiográfico de ficción.

La trayectoria del género no ofrecía dudas desde Virgilio sobre la legitimidad indiscutible del procedimiento alegórico o, por mejor decir, alusivo $^{30}$, y a ello nos vamos a referir enseguida. El mecanismo regía con matemática precisión cuando entraba el paso de danza pastoril. Escritores que se comunican entre sí bajo la denominación y el seudónimo bucólicos: Cetina-Vandalio contestando a Urrea-Iberio «estas causan, pastor, mi des-

28 La evaluación estadística procede de nuestro estudio sobre La poesia pastoril española del siglo $X V I$, tesis doctoral leída en la UNED, de publicación próxima.

${ }^{29}$ Op. cit., p. 210.

${ }^{30}$ Los dos conceptos, referidos a la pastoral como género de clave, vienen a confundirse: pero fuera de aquí tienen distinto valor, por más que se empleen con frecuencia como términos equivalentes. E. CARRARA ha precisado así el sentido de lo alegórico en la égloga: «Ma quando si dice che l'ecloga è allegorica, occorre non pensare alla integrazione della finzione reale con la figurata, como accade nell'alegoria medievale: bensi che essa proviene da una combinazione di due elementi diversi: l'uno puramente pastorale, l'altro puramente alusivon (La Poesía Pastorale, tomo IV de la Storia dei generi letterari italiani, Milano, Francesco Vallardi, s.a., (1909), p. 24). La conjunción de los dos elementos es lo que confiere a la égloga su estatuto particular. 

su admirado Montemayor-Luscitano en la epistola de su Floresta para evocar, como expresión superior del sentimiento de la amistad, un ideal de vida campestre común, compartido con sus Marfira y Marfida; Lomas CantoralMelibeo ensalzando la gloria de los poetas vallisoletanos en el «Canto Pinciano", cantores todos, con sobrenombre bucólico, de la belleza inmortal de sus respectivas amadas (Belisas, Alcidas, Filenas, Tirrenas...). Príncipes y miembros de la más alta nobleza complaciéndose en ser invocados, e incluso nombrándose a sí mismos en sus ejercicios literarios, con los ilustres apellidos pastoralizados: Lavinio, el príncipe de Ascoli don Luis de Leiva; Sesenio, el duque de Sessa don Gonzalo Fernández de Córdoba (1524-1578); Montano, el marqués de Montesclaros, etc. Acontecimientos sociales de la envergadura de unas bodas reales (la unión de Felipe II con Margarita de Austria) festejándose al modo bucólico, como en la composición de Lope que se encabeza así: «Romance a las ventv/rosas bodas que se celebraron e/ la Insigne Ciudad de/ Valencia./ Va nombrando todos los Grandes que se hall-/ron en ella debajo de nombres/Pastoriles ${ }^{31}$. Toda la sociedad quinientista afecta a la cultura dominante se veía en aquellos espejos que devolvían la imagen trasmutada a lo bucólico; nada tiene de extraño el apego particular de los escritores a un modo de figuración que tan profundo arraigo social alcanzaba ${ }^{32}$.

Una moda, sí, pero acogida con entusiasmo y fervor; frívola, sin duda, para los frivolos, pero vía fecunda también para expresar la intimidad ${ }^{33}$. La envoltura pastoril pasó a ser procedimiento poco menos que imprescindible para unir la vida a la poesía de manera efectiva, de un modo que la convención aceptada por todos hacía representación casi directa. El ejercicio

"Valencia, Diego dE LA TORRE, 1599; un ejemplar se conserva en el British Museum de Londres, c. 63 a 2 (Cfr. J. SıMÓn Díaz, Impresos del siglo XVI: Poesia, Cuadernos Bibliográficos, Madrid, CSIC, XIII, 1964, ficha núm. 306).

"2. Blanco Sánchez ha pintado con graciosa ironía la fruición de aquella transformación a lo pastoril: «Dificilmente encontramos poeta de esa época que no utilice dos o más seudónimos para ocultar el nombre suyo y el de sus amadas. Claro está, se acude por lo regular a Virgilio o a los poetas toscanos para obtenerlo prestado y, asi, como si todos hubieran comprado los vestidos para un baile de disfraces en una misma tienda. Cinco personas compraron cinco trajes de Marfidas y de Marfiras (que la direrencia estaba sólo en un pequeño cintillo imperceptible); otras tantas, severos trajes de Damones, Dóridas, Amarilis, Filis, Galateas, Lícidas, Tirsis, Fílidas y una muchedumbre deseosa de vestirse para el baile con trajes pastoriles dejó la tienda vacía» (Entre Fray Luis y Quevedo. En busca de Francisco de la Torre, Salamanca, Atlas, 1982, p. 672).

${ }_{33}$ «Fue una moda sin duda -escribe J. F. MONTESINOS-; pero una moda puede ser a su vez un estilo y al emplear esa palabra que suele añadir a las obras literarias una nota de infamia debemos ser cautos; no todo es frivolidad en las modas. Un tipo de creación generalmente trae consigo la repetición casi mecánica, atolondrada e inepta; pero la obra en que el espiritu de toda una tendencia cristaliza permanece perennemente» (Introducción a Poesias líricas de Lope de Vega, Madrid, Clásicos Castellanos, 2 vols., 1960 y 1963; I, p. XXIV). 
de travestismo a lo pastoral significó bastante más que un simple artificio y juego de ocultamiento. Trajo consigo, por el contrario, la posibilidad de la declaración pública de la intimidad más personal, ahora velada sólo porque la época no permitía ir más allá - con aquellos ropajes que apenas podían encubrirla. El hecho de ser de uso común y hasta fabricados en serie, como diríamos hoy, no implicaba la anulación de la voz personal, pues en medio de tantas similitudes lo individual podía resultar realzado para un lector habituado a las claves particulares del género. Un caso parecido, valga la comparación, a la uniformidad en el vestir que se observa en algunos pueblos del planeta: sólo la lejanía geográfica y cultural nos borra las diferencias personales, suprimidas para nosotros por lo aparente. Con la necesaria perspectiva histórica y cultural hemos de ver también aquellos disfraces renacentistas. La concordancia de las actitudes y los modos de sentir no procede sólo del hábito, sino de la conjunción de las corrientes estéticas y de pensamiento (petrarquismo, humanismo, neoplatonismo, etc.), en tiempos en que la imitación imponía unos senderos universales. Dentro de estas coordenadas, la bucólica satisfacía bien las apetencias comunicativas de lo personal ${ }^{34}$.

\section{LA TRADICIÓN ALUSIVA}

La disposición para historiarse a sí mismo parece inherente a la materia bucólica $^{35}$. Es el propio Teócrito quien instaura este uso cuando en el idi-

${ }^{34}$ Así lo advierte LOPEZ EstradA: «La égloga es una vía de libertad, al mismo tiempo que un disfraz. El caballero Garcilaso puede ser Salicio y Nemoroso. El "disfraz", como se le ha llamado, es un convencionalismo aceptado por todos y que el compromiso social convierte en verdad artística. Esto que a nosotros, como biznietos del Romanticismo, puede parecer un procedimiento negativo, no lo era para los contemporáneos de Garcilaso. Aunque resulte paradoja, este disfraz es un medio para expresar la intimidad" ( SSiglos de Oro: La literatura pastoril", Boletin Informativo de la Fundación Juan March, 170 [mayo, 1987], 27-34, p. 30). Nadie mejor que Salinas ha sabido explicar el verdadero ser de este pastor literario, lo que se esconde tras esa tantas veces incomprendida transfiguración campestre: «El pastor de las églogas no es un pastor, como bien saben todos los autores de églogas. Es un cortesano. Entonces ¿por qué se viste de pastor? Porque había en su alma una inclinación a lo natural y, como hombre completo del Renacimiento que es, no renuncia ni a su ser ni a su deseo de ser, ni a la realidad de ser cortesano ni al deseo de ser pastor [naturalmente, en posesión de la virtus y la dignitas humanistas] ¿Puede por tanto lo pastoral ser considerado un nuevo disfraz? Sólo hasta cierto punto. Diriamos que no es un disfraz que el poeta alquila o compra, sino uno que se saca de sí mismo, que es otro aspecto, otra forma de realidad. Cuando un poeta crea un poema pastoril verdaderamente hermoso, es porque ha sabido combinar en él el arte y la naturaleza, las dos vertientes que viven en su alma) (La realidad y el poeta, Barcelona, Ariel, 1976 , p. 111).

${ }^{35}$ Así lo declaraba en 1548 el preceptista francés Thomas Sebillet en su Art Poétique 
lio VII, «Las fiestas Talisias», se representa bajo el nombre de Simiquidas y, a lo que parece, a su amigo Leónidas de Tarento con el de Lícidas ${ }^{36}$.

El carácter referencial se consolidará en las Bucólicas virgilianas. En la Ég. I, que es en lo fundamental un canto de alabanza a Octavio (sin nombrarlo: "Hic illum uidi iuuenem, Meliboee, quotannis / bis senos cui nostra dies altaria fumant", v. 42-43 ${ }^{37)}$ aparecen Títiro (nombre tomado de Teócrito, Ids. III y VII) y Melibeo (creado por Virgilio) ${ }^{38}$. El poema viene a ser una evocación del conflicto del reparto de tierras desde una doble perspectiva y con el autor detrás de ambas: Títiro, enteramente reconocido; Melibeo, protestando por la confiscación.

Françoys:

[...] ce Pöéme qu’ilz ont apellé Eclogue, est plus souvent un Dialogue, auquel sont introduis Bergers et gardeurs de bestes [...] soubz allégorie tant clére, que lés desseins dés noms, dés personnes, et l'adaptation propre dés propos pastoraus aus choses soubz iceus entendues et déduittes, lés facent voir tant clérement, comme s'apperçoit la peinture soubz le verre.

(Cit. por F. LOPEz Estrada, Los libros..., op. cit., p. 429).

Por lo que concierne a la novela pastoril, LOPEZ ESTRADA advierte que los libros de pastores perderán bien pronto el sentido autobiográfico (ib., p. 301). Por el contrario, Avalle-Arce piensa que tras las primeras creaciones novelescas sigue plena su idoneidad como fórmula de comunicación autobiográfica; y así, refiriéndose a las de Gálvez de Montalvo, Bernardo de la Vega, Lope de Vega y Gaspar Mercader, sostiene que en ellas «el autor ahora es bucoliasta sólo en segundo término; antes que nada es historiador de si mismo" (op. cit., p. 142). BENfTEZ Claros también insiste en la importancia de la explicación historicista: «Si sentamos el hecho de concebir la novela pastoril como definitivo arte de evasión para los autores y para el público, de plasmación de unos ideales entrañablemente sentidos por unos y otros, cabe historiar el género en función de los depósitos, de los sedimentos que los autores hayan dejado de su propio sentir y vivir en los personajes por ellos pensados y encarnados" (op. cit., p. 108). En cuanto a la poesia, la trayectoria seguida no ofrece dudas: en la medida en que el asunto pastoril pierde su frescura, el valor autobiográfico va decayendo en favor de lo puramente imaginado, aunque siempre es posible que autores aislados rescaten el yo auténtico de la progresiva despersonalización que determina el rasero de la imitación sin inventiva.

${ }^{36}$ Se ha pensado con frecuencia que con esta fórmula Teócrito no hacía sino llevar a la práctica literaria algo que ya era habitual en su vida real, como perteneciente a una sociedad de amigos - equivalente a las posteriores academias literarias del Renacimiento-cuyos miembros, bajo disfraz pastoril, se ocupaban indistintamente de la creación poética y de la crítica. Esta tesis de la "mascarada bucólica» como arranque inmediato del género bucólico es sólo una entre las diversas teorías que han pretendido explicar sus orígenes. M. BRioso ha expuesto el estado actual de la cuestión de las identificaciones de este idilio y de la pastoral teocritea en su conjunto (Bucólicos griegos, Madrid, Akal, 1986, pp. 105-108), subrayando, no obstante, su escepticismo acerca del valor de las mismas (véanse también las pp. 16-17, 88 y 100).

${ }^{37}$ Bucólicas, ed. de Mariluz Ruiz de Lóizaga y Víctor José Herrero, Madrid, Gredos, 1983.

38 Este es un pequeño propietario desposeído por Octavio al distribuir tierras entre los veteranos de la guerra contra Bruto y Casio; Títiro (se nombrará a sí mismo Virgilio de esta manera al comienzo de la Eg. VI, v. 4), merced a unas gestiones en Roma ante Octavio, ha obtenido la promesa de no ser expoliado. 
La Ég. IV comporta también un posible significado biográfico, aunque no sea fácil la identificación del niño cuyo nacimiento se festeja, haciéndolo coincidir con el advenimiento de una nueva Edad de Oro ${ }^{39}$. Y de nuevo se ha visto a Virgilio representado en el Menalcas de la Ég. V, especialmente en los versos 56-80, de alabanza a Dafnis, dios de los pastores: el mantuano lo ensalza como instaurador de un nuevo modelo de vida y digno, por tanto, del culto de su entusiasta admirador. Por otro lado, puede considerarse también esta égloga como una nueva alabanza de Virgilio a los fundadores del Imperio, en la persona ahora de Julio César ${ }^{40}$.

Otra vez se encuentran en la Ég. IX las referencias al reparto de las tierras de Cremona, del que no había quedado exenta Mantua, pese a las gestiones de Virgilio ante Alfeno Varo, sucesor de Polión en la Cisalpina; Meris se queja de ello:

«O Lycida, uiui peruenimus, aduena nostri (quod numquam ueriti sumus) ut possessor agelli diceret: «haec mea sunt; ueteres migrate coloni».

(v. 2-4).

Y se hace mención de Menalcas, que ha salvado sus tierras a pesar de todo, en referencia clara al propio Virgilio (se repite el nombre de la Eg. V), cuyas cualidades como poeta se alaban.

${ }^{39} \mathrm{La}$ indeterminación de personalidad favoreció las atribuciones más diversas, desde la supuesta referencia a un hijo de su amigo y protector Asinio Polión (acaso Galo, o Salonino) hasta la del nacimiento de Jesucristo (interpretación de la Iglesia, en su suposición de que Dios se había también manifestado a través de los gentiles mediante símbolos). La bibliografía sobre el tema es muy abundante; véanse los trabajos de H. JEANMAIRE, Le messianisme de Virgile, Paris, J. Vrin, 1930; P. CourCelle, "Les eségèses chrétiennes de la quatrième Eglogue», Revue des Etudes Anciennes, LIX (1957), pp. 294-319; M. MANSON, "L'enfant et l'Age d'Or. La IV Eglogue de Virgile", en R. Chevallier (ed.), Présence de Virgile, Paris, (Actes du Colloque de l'Institut d'Etudes Latines de l'Université de Tours), Paris, Les Belles Lettres, 1978, pp. 4962. Para ésta y otras cuestiones sobre la fortuna de Virgilio en la Edad Media sigue siendo aportación fundamental la obra de D. CompareTt, Virgilio nel Medio Evo, Livorno, 1872, 2 vols.

40 En opinión de Antonio Tovar (Introducción a la Eg. V de su ed. de las Bucólicas, Madrid, Clásicos Emérita, 1951, p. 68), el dato que aparece en los versos 29-31, por el que se atribuye a Dafnis la introducción en Roma de los cultos y ritos de Baco, es extraño a la leyenda del mítico pastor; debe verse entonces en Dafnis la imagen de César. También lo interpreta así Ernst Bickel (Historia de la literatura romana, Madrid, Gredos, 1982, p. 605), al igual que otros comentaristas. La propia canción de Menalcas parece encajar además con la deificación popular de César a partir de su muerte, convertida en oficial con la ley Rufrena del año 42 a. $C$. 
En la Ég. X hay un refrendo explícito al sentido biográfico de la pastoral cuando el protagonista se incorpora a la ficción bucólica sin siquiera revestirse del habitual disfraz pastoril y aparece con su propio nombre [C. Cornelio] Galo (ya glorificado en el canto de Sileno de la Ég. VI, v. 64-73), y el pastor Menalcas (Virgilio nuevamente) muestra su pena amorosa ${ }^{41}$.

Existe, como se ve, una tendencia en el mantuano a representar como pastores $o$ introducir entre ellos a personajes de la alta sociedad y del mundo de las letras ${ }^{42}$; como afirma M. Dolç, «bajo la apariencia exterior de las Bucólicas se puede reconocer fácilmente toda una sociedad romana, hoy oscurecida a nuestros ojos, que los contemporáneos del poeta debieron estimar como un nuevo mérito" ${ }^{43}$. No obstante, si bien determinados pasajes admiten la interpretación per allegoriam, debe procederse aquí con mucha cautela: primero, porque la ambigüedad de algunas alusiones no permite identificar con seguridad a ciertos personajes (las Égs. IV y V son las más oscuras a este respecto), y segundo, porque no es común a todas las églogas el carácter alegórico ${ }^{44}$.

Algunos comentaristas, señala Carrara ${ }^{45}$, han llegado a acusar a Virgilio de poner su producción bucólica al servicio de la adulación y de la representación de sus asuntos particulares, marcando un camino a sus seguidores de la época imperial, y deformando para siempre el ideal de la poesía pastoral. La glorificación de Nerón por Calpurnio Sículo y las alusiones de las Einsidlenses, con la posterior imitación de las églogas de Nemesiano, parecían confirmar la decadencia y las consecuencias de un uso sesgado de lo bucólico. Pero es éste un resultado no necesariamente derivado del procedimiento alusivo, porque las églogas no eran para el mantuano sólo instrumento al servicio del enmascaramiento, con la connivencia complaciente del receptor. Su

${ }^{41} \mathrm{La}$ amistad entre el mantuano y el malogrado poeta-soldado (cuyo influjo en las $\mathrm{Bu}$ cólicas debió de ser apreciable en cada una de las diez églogas, que incorporan, al parecer, diversos pasajes de sus perdidas poesías) fuerza a nuestro autor a romper el convenido ocultamiento tras el seudónimo para exhibir aquella triste historia directamente, aunque sin perder el marco y los habituales elementos bucólicos.

${ }^{42}$ Recalca BICKEL la diferencia en esto respecto de Teócrito: «en Virgilio los que llevan las máscaras pastoriles no son propiamente poetas amigos situados en un plano de igualdad, sino que en su lugar aparecen protectores y altos dignatarios que le libraron de la penuria»" (ib., loc. cit.).

43 "Sobre la Arcadia de Virgilio", Estudios clásicos, IV (1958), 242-267, p. 253.

4 Asi lo ha pretendido L. HeRmann (Les masques et les visages dans les Bucoliques de Virgile, Bruxelles, Revue de l'Université de Bruselles, 1930). Pero las églogas no son, advierte Dolç, ni «un libro cifrado ni un carnaval romano de la época augustal» (op. cit., p. 253); hay que conducirse, por tanto, con cuidado en la interpretación de sus claves, según nos previene A. ROSTAGNI: «noi non possiamo tradurre senz'altro gli elementi della figurazioni poetica in elementi di storia, nè servicene del tutto ai fini della biografia virgiliana" (Storia della letteratura latina, Torino, UTET, 1964, 3." ed., 3 vols., II, p. 60).

is Op. cit., p. 9. 
transformación en eso se debe a la labor de autores epigonales, que no hacían, al cabo, sino aprovechar para sus propósitos algo que estaba ya alli ${ }^{46}$.

El carácter alusivo era, por tanto, virtualidad inherente al género, pero de ningún modo exigía actualización permanente y universal; de hecho, Virgilio sólo llegó a hacerla efectiva en algunas composiciones. Se cuidaron de advertirlo ya los comentaristas antiguos: «In bucolicis Vergilii neque nusquam neque ubique aliquid figurate dici, hoc est per allegoriam», señala Donato en su Vitae Vergilianae, para añadir que esto sólo ocurre en el contexto de referencia a Augusto y la recuperación de sus campos, "vix enim propter laudem Caesaris et amissos agros haec Vergilio conceduntur, cum Theocritus simpliciter conscripserit» ${ }^{47}$. La misma interpretación da Servio al comienzo de sus comentarios, subrayando también la diferencia con Teócrito: «Et alliquibus locis per allegoriam agit gratias Augusto, vel aliis nobilibus, quorum favore amissum agrum recepit; in qua re tantum dissentit a Theocrito" ${ }^{48}$; y luego, al comienzo del comentario de la Ég. I, insistirá en el principio de la alegoría ocasional: «Et hoc loco sub persona Tityri Virgilium debemus intelligere; non tam ubique, sed tantum ubi exigit ratio"s.

Durante la época medieval prevaleció, de todos modos, la égloga alusiva o alegórica; hasta el punto de considerarse, dice $\mathrm{A}$. Tissoni ${ }^{49}$, como la condición esencial de la poesía pastoral. El testimonio de Petrarca resulta bien explícito cuando escribe a su hermano Gherardo (monje cartujo en Montrieux) en 1348 una carta para explicarle lo que quiso decir en la Ég. I de su Bucolicum carmen ${ }^{50}$. La alegoría abarcaba aquí un campo muy variado: desde alusiones a hechos y personajes de la época (Égs. II, V, VI, VII, VIII,

46 Lo anota al punto CARRARA: «Converrá dire soltanto che la malattie dei padri s'aggravano nei figli e che Virgilio non ha maggior colpa delle adulazioni di Calpurnio o delle allegorie del Boccaccio, di quanto Teocrito abbia delle sue: ma bisogna tuttavia convenire che il germe del male era proprio del ceppo vecchio, in Teocrito stesso" ( $i b$.).

${ }^{47}$ Ed. de Jacob Brummer, Leipzig. 1912, pp. 16-17.

4 Ed. de G. Thilo y H. Hagen, Servii Grammatici qui feruntur in Vergilii Carmina commentarii, Leipzig, 1881-87, 3 vols., 1 , p. 2.

49 Antonia Tissoni Benvenuti, “La restauration humaniste de l'églogue: l'école guarinienne à Ferrare", Centre d'Etudes de la Renaissance et de l'Âge Classique, Le genre pastoral en Europe du XV' au XVIr siècle, Actes du Colloque International (Saint-Etienne 1978), SaintEtienne, Université, 1980, 25-33, pp. 25-28.

3) «Sed quoniam id genus est quod nisi ex ipso qui condidit auditum, intellegi non possit, ne te inutiliter fatiges, primo quid dicam, deinde quid intendam brevibus explicabo» $(\mathrm{F}$. PETRARCA, Le familiari, ed. de V. Rossi, Firenze, Sansoni, 1934, tomo XI, Lib. X, Ep. IV, p. 304). El modelo alegórico petrarquista, advierte Tissoni, no satisfacía plenamente a Boccaccio, que lo juzgaba no ajustado a la tradición clásica, y fue ocasión para alguna discusión en la época, siempre resuelta en favor de la línea de Petrarca; así escribía, por ejemplo, Antonio de Faenza, al comienzo de una de sus églogas, en 1439; "Verum, ut Boccaccius reffert sua quadam eleganti epistola [alusión a una muy conocida a Fray Martino da Signa], non singuli interlocutores aeglogarum sub aliqua significantia reponuntur. Volui tamen ego Frnaciscum P[etrarcam] poetam elegantissimum, imitari, apud quem nihil dabitur in eiusmodi dicendi genere absque personali significantia" (cit. por Tissoni, pp. 27-28). 
$\mathrm{XII}$ ), a asuntos relacionados con cuestiones literarias (IV, $\mathrm{X}$ ) y con la intimidad personal (I, III, IX, X, XI). El modo bucólico se consideraba entonces el procedimiento adecuado para representar los casos personales, los sucesos de la vida presente, las alabanzas de los poderosos. No extrañará por eso que, como ya lo hizo el de Arezzo, reflejara las luchas religiosas o políticas; así en las Coplas de Mingo Revulgo, en la Égloga de Francisco de Madrid, o en determinadas églogas latinas de la Italia renacentista. Eran, por lo demás, una fuente de placer sobreañadido para lectores deseosos más de poner a prueba su capacidad de observación y análisis que de saborear los deleites de la ficción pastoril; lo resaltó oportunamente Hernando del Pulgar, en su comentario a las Coplas ${ }^{51}$. La imitación renacentista reconduciría después el significado del poema bucólico a un ámbito más acorde con su sentido clásico, en el marco del canto amoroso, pero mantuvo vigente la capacidad alusiva, dentro siempre de un compacto sentido de lo pastoril, a lo que todo lo demás quedaba subordinado ${ }^{52}$.

Los comentaristas virgilianos renacentistas ${ }^{53}$ mantenían, no obstante, la

51 "Y en esta Bucólica, que quiere decir cantar rústico y pastoril, quiso dar a entender la doctrina que dicen de color de la rusticidad, que parecen decir; porque el entendimiento, cuyo oficio es saber la verdad de las cosas se exercite inquiriéndolas, y goce como suele gozarse cuando ha entendido la verdad de ellas" (Dedicatoria al Conde de Haro, Condestable de Castilla, Obras de Fernando del Pulgar: Letras. Glosa a las Coplas de Mingo Revulgo, Madrid, Clásicos Castellanos, 1929, 2 vols., II, pp. 159-160).

${ }_{52}$ Este, y no otro, era también el significado de lo alegórico en Virgilio, decía el latinista alemán de comienzos del siglo xIX, F. A. G. SPOHNio en sus «Prolegomena ad Carmina Bucolica Virgilii" (Opera P. Virgilii Maronis, ed. de Christ. G. Heyne y Ge. Phil. Eberard Wagner, Leipzig, 1830 (reimpr. Hildesheim, Georg Olms, 1968, pp. 21 y ss.): «Primum enim, dum imitatur Theocritum, quae hic dixerat simpliciter, ille traduxit in suum usum ita, ut alium sensum, aliud consilium iis subesse vellet, per artificium tecte ad quaedam alludens. Hinc allegorica interpretatio orta. Sed saepenumero nonnisi personas esse vult, quas introducit, non ut per totum carmen quasi personatos sese aut alios sistat, sed ita ut plerumque is haec illa adscribat, quae sola ad se aut alium quempiam ita referri debent, ut in ceteris nihil restet de personato, sed res redeat ad pastores» (p. 21). El recuerdo de Servio subyace sin duda a sus juicios. Y a él remiten asimismo las puntualizaciones sobre el empleo de la alegoría: utilizada sólo cuando el autor se ve forzado a ella por necesidad, como cuando alude a la pérdida de sus tierras ( Refutandae enim sunt allegoriae in bucolico carmine, nisi cum, ut supra diximus [en el comentario a la Eg. I, v. 1], ex aliqua agrorum perditorum necessitate descendunt"; comentario a la Eg. III, v. 20).

También Ch. G. HEYNE, autor de esa misma edición virgiliana, insistía en su introducción ( (De carmine bucolico», pp. 3-20) en la no subordinación de las églogas a la alegoria, porque por encima de ella impera el canto a la vida sencilla, pp. 19-20.

Pero en la égloga cortesana el carácter alusivo fue algo consustancial a la composición, por más que la difícultad a que alude Hernando del Pulgar no siempre fuera tan subida, pues no pocas veces, en especial tratándose de composiciones laudatorias, la personalidad de los personajes representados era desvelada desde el comienzo; así, por ejemplo, en la Égloga de Francisco de Madrid (ed. de Alberto Blecua, "La Égloga de Francisco de Madrid en un nuevo manuscrito del siglo XVI», Serta Philologica Fernando Lázaro Carreter, Madrid, Cátedra, 1983, 2 vols., II, 39-66, p. 48).

${ }^{33}$ Véase Annabel PATterson, Pastoral and Ideology. Virgil to Valéry, Berkeley-Los An- 
tradición interpretativa; Poliziano, por ejemplo, advertía en las anotaciones a su edición de las Opera del mantuano (Roma, 1471) que «totus liber [el de las Bucólicas] per allegoriam intelligitur $)^{54}$. En el mismo sentido se manifestaba Vives en su Interpretatio allegorica in Bucolica Virgilii, 1537, contradiciendo las restricciones de Servio: «Accedit huc, quod res ipsae plerisque in locis satis testantur, non simpliciter dici, sed figurate; quo magis miror, Servium Honoratum nullas allegorias admittere, nisi de agris deperditis: quae aliis multis de rebus manifestissimae sunt» ${ }^{s 5}$. Ésa es la razón, según señala Josef Ijsewijn, por la que el humanista español, tan severo con la literatura de ficción, no condenara tales composiciones por paganas y gravemente eróticas, $y$, por el contrario, las siguiera considerando, con los pedagogos de su tiempo, como el texto por excelencia para la iniciación en la poesía latina ${ }^{36}$; el alegorismo, comenta el profesor de Lovaina, aseguraria, para Vives, la transcendencia de aquellos poemitas ${ }^{57}$. Bastantes años después, Lope de Vega seguía proclamando, en la introducción a su Égloga amorosa, aquel mismo carácter alusivo con el que el poema bucólico trascendía el original ámbito rústico de referencia ${ }^{58}$.

El éxito cortesano de fiestas y dramatizaciones pastoriles de corte contribuyó también a reforzar el auge universal de una figuración bucólica que la sintonía con un determinado catálogo de valores espirituales había puesto de actualidad, no exenta en su caso de una cierta nota de frivolidad, reflejo de ese mismo arraigo. Descubrir tras los nombres pastoriles la personalidad escondida podía seguir siendo un juego divertido para unos cortesanos que ya antes habian hallado solaz en la refinada pastorela medieval; un entretenimiento añadido que incrementaba el interés por aquellas modalidades del género de mayor proyección social inmediata, como eran las piezas de carácter escénico compuestas con ocasión de algún evento público o cortesano $^{59}$.

geles, Univ. of California Press, 1987, pp. 62-106, donde estudia la visión humanista de Virgilio a través de algunos comentarios a la sección bucólica de sus Opera.

Cit. por A. Patterson, p. 82.

Ibidem, p. 89.

" "Vives et Virgile», en R. Chevallier (ed.), Présence de Virgile, cit., 313-321, p. 316.

"7 "Aưx yeux de Vivès, l'argument décisif en faveur de l'allegorisme est de nature historique et littéraire: les thèmes chantés dans les églogues sont trop legers, trop minces pour avoir pu plaire aux intellectuels romains comme Gallus, Asinius, Pollio ou Auguste lui-même, si quelque sens plus profond n'y était pas caché sous le voile pastoral» (ib., p. 320).

${ }_{5 \mathrm{~N}}$ «Las églogas contienen más de lo que muestra el exterior, como se ve en las de Virgilio, que son alegóricas, y en alabanza de los emperadores o personas ilustres y otros sujetos, debajo de estilo pastoril, en que el poeta imitando se adelantó a Teócrito, de quien dice Quintiliano que ignoró, no sólo las plazas de las ciudades, sino las mismas ciudades. Mas discúlpale haber sido el primero que las escribió, y cuando el mundo estaba menos poblado y más al principio de su creación; y asi, naturalmente los pastores eran y debían pintarse más rudos») (BAE, XXXVIII, p. 306a).

${ }_{59}$ Desde finales del siglo $\mathrm{XV}$, y en creciente auge, venían representándose en las fiestas 
También la novela pastoril procedió con clave biográfica, y de ello hicieron profesión de fe sus autores, bien fuera para incitar a la lectura con el premio del descubrimiento, bien para fortalecer la credibilidad de las historias narradas, o por ambas cosas. Montemayor advertía al lector en el «Argumento» de la Diana que allí «hallará muy diversas historias de casos que verdaderamente han sucedido, aunque van disfraçados debaxo de nombres y estado pastoril ${ }^{60}$. Y Cervantes hacía notar en el Prólogo de $\mathrm{La} \mathrm{Ga}$ latea cómo «muchos de los disfrazados pastores della lo eran sólo en el hábito" ${ }^{61}$. Lope, por su parte, no se cansó de proclamar que en La Arcadia los personajes, bajo el vestido pastoril, eran cortesanos, cuando no príncipes, porque «es historia verdadera, que yo no pude adornar con más fábulas

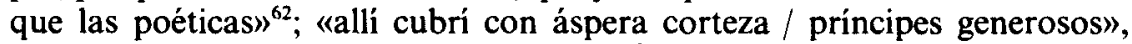
recordará, años después, en La Filomena ${ }^{63}$.

cortesanas de las cortes italianas églogas dramatizadas, alusivas en su mayoría a situaciones y personajes del presente (muchas veces miembros o asiduos de la propia corte). La Questión de amor, publicada en Valencia (1513) por Diego Gumiel, desarrollada como una crónica de la vida en la corte de Nápoles en los primeros años del siglo, se asienta sobre el mismo juego de ocultaciones controladas y fácilmente descifrables donde la ambigüedad entre ficción y realidad entraba como uno de los alicientes del producto (cfr., Juan OLEZA SIMO, «La tradición pastoril y la práctica escénica cortesana en Valencia (I): El universo de la églogam, en J. OLEZA Sıмó (coord.), Teatros y prácticas escénicas, I: El Quinientos valenciano, Valencia, Institució Alfons el Magnànim, 1984, pp. 189-217; y "La corte, el amor, el teatro y la guerra», Edad de Oro, V, (1986), pp. 149-182). En España, desde los inicios encinianos, la fiesta cortesana hizo también suya - aunque con menor convicción y asiduidad que en Italia, y aun que en Inglaterra y Francia - la representación de las églogas, «el primer signo de identidad del teatro cortesano», al decir de Oleza («La corte...», p. 171); para una panorámica de conjunto véase: George IRVING DALE. "Games and Social Pastimes in the Spanish of the Golden Age", Hispanic Review, VIII (1940), pp. 219-241; Manuel SITO ALBA, "El teatro en el siglo XVI (desde finales de la Edad Media a comienzos del siglo XVII)", en J. M. Diez Borque (ed.), Historia del teatro en España. Madrid, Taurus, 1983, I, pp. 155-471; J. M. DIEz BORQUE, Los géneros dramáticos en el siglo XVI (El teatro hasta Lope de Rueda), Madrid, Taurus, 1987, pp. 53-65; Juan Rodriguez, tesis doctoral sobre la comedia pastoril española, leida en marzo de 1990 en la Universidad Complutense. Otro tanto puede decirse de las piezas dramáticas pastoriles en Francia, camino importante hacia su teatro nacional; valga como ejemplo la Bergerie de Ronsard, representada probablemente en Fontaineblau en 1564, en la que la bucólica aparece sobre todo, según explica J. HOSLE, como «loor cortesano, panegírico y medio de expresión de un juego de disfraces fácilmente descifrable para los iniciados" ("La literatura pastoril europea", A. Buck (dir.), Renacimiento y Barroco, en Literatura Universal, dirigida por K. von See, Madrid, Gredos, 1982, tomos 9-10, 268-292, p. 281).

${ }^{\infty}$ Ed. de F. López Estrada, Madrid, Cásicos Castellanos, 5." ed., 1970, p. 11.

${ }^{61}$ Ed. de J. B. Avalle-Arce, Madrid, Clásicos Castellanos, 1968, 2 vols., I, p. 8.

62 Dedicatoria a Juan de Arguijo de las Rimas (Madrid, 1602), ed. cit., fol. 244v.

63 II Parte, BAE, XXXVIII, p. 490a. También lo afirma Tirso de Molina en La fingida Arcadia por boca de Pinzón:

No ignores

que en la Arcadia disfrazó

metafóricos pastores 


\title{
5. CONCLUSIÓN
}

El procedimiento alusivo tiene, por tanto, un peso innegable en la concepción del texto poético en la tradición del género. En él van expresados la ocasión y el motivo de la obra, velados -en proceso de elusión de la anécdota - por la envoltura pastoril. Bajo este enfoque, nos parece lícita $\mathrm{y}$, en consecuencia, válida toda interpretación que tenga en cuenta las posibles equivalencias entre escritura y vida. Distinta es la opinión de Iglesias Feijoo en su ya citado análisis de la garcilasiana Égloga $I$ : «Esa fusión o confusión entre vida y poesía ("Amor y poesía cada día") ès un producto de nuestra mirada actual, que nos hace como más bellos los pasajes que nos parecen autobiográficos, aquellos en que nos parece descubrir el aleteo del sentimiento real del poeta, su emoción personal, su implicación vital» ${ }^{64}$. $\mathrm{La}$ herencia de casi dos siglos de una crítica marcadamente romántica ha definido, sin duda, una concepción del género influida por tales principios; planteamiento, por lo demás, justificado en esta clase de obras, tan necesitadas, por su fuerte idealización y por la estrecha imitación de los modelos, de un factor de autenticidad. No hay duda de que tal enfoque interpretativo ha contribuido a reafirmar esa visión de la poesía pastoril; pero no es ésta una cualidad advenida a posteriori, fruto sólo de determinada interpretación histórica. Como acabamos de ver, no es sólo nuestra mirada actual la que nos hace ver estrechos lazos entre la vida y aquellos textos poéticos; la lectura alegórica no es de ahora ${ }^{65}$. La historia del género nos muestra la

\author{
Lope, y que si apacentaban \\ los ganados que regian, \\ vistiendo telas mostraban \\ así, el valor que encubrian \\ más que el que representaban.
}

(Comedias de..., NBAE, ed. de Emilio Cotarelo, Madrid, Bailly-Baillière, 1906, I, Jornada III, p. 452a).

of Op. cit., p. 64.

6s Era en la época opinión común que en la poesía siempre había un fondo de verdad, "porque las cosas en lo literal falsas, muchas vezes se miran verdaderas en la alegoria», decía LOPEZ Pinciano (Filosofia Antigua Poética, ed. de Alfredo Carballo Picazo, Madrid, CSIC, 1961, 3 vols., I, p. 162), bien fuese por representar sentimientos universales, bien por reflejar experiencias, sentimientos o aspiraciones personales del poeta. En lo primero pone el acento IGLESIAS FEIJOO (p. 65) para proponer otra forma de enfrentarse a la obra de Garcilaso, libre "de las delicuescencias amorosas de que suele resvestírsela"; y menciona la autoridad de Spitzer, cuando dice que, antes del Romanticismo, el poeta cree que su poesía es urepresentativa [...] de sentimientos universales» y que "consiste en palabras pertenecientes a un lenguaje dado». Pero esto no elimina, creemos, la vinculación, en la raíz de estos poemas bucólicos, con una realidad concreta, según se ha visto. 
elevada frecuencia con que el escritor se representaba a sí mismo en sus personajes, con la complicidad de sus lectores y amigos, también incorporados asiduamente a la misma operación disfrazadora. Por eso podemos decir con justeza, siguiendo a Salinas, que ese disfraz no es alquilado ni comprado, sino sacado del propio poeta, como proyección de su mundo personal (el de su intimidad y el de su circunstancia).

Excluida la triple identificación autor-narrador-personaje, la modalidad autobiográfica pura, la poesía pastoril se inclina decididamente por la opción de los relatos autobiográficos de ficción, basados en la semejanza entre la historia del personaje y la del autor; el paralelo puede establecerse, según señala Romera ${ }^{66}$, ya por informaciones exteriores, ya por la correspondencia con otros textos del escritor. Así, por ejemplo, en la ahora discutida equivalencia de Garcilaso con determinados personajes suyos, y sin entrar en la polémica, podemos comprobar cómo el lector establece aquella relación tanto por las referencias deducibles de los textos de otros poetas ${ }^{67}$ y las aportadas por la historiografia literaria, como por las semejanzas entre los textos del propio poeta. El caso de Nemoroso es ilustrativo al respecto. Representa el dolor por la muerte de la mujer amada, Elisa, en las Égs. I y III; y si convenimos en admitir en los sonetos la equivalencia del sujeto lírico que confiesa su dolor por la dama muerta y el propio poeta, surge inevitable la asociación identificativa de personaje y autor. Y tanto más cuando se observan determinadas correspondencias en la expresión de ese dolor (el hecho de que haya un fondo tópico común es indiferente a lo que ahora importa ${ }^{68}$.

Op. cit., p. 27.

67 V. gr., de la Eg. V, «Salicio», de Herrera; la «Elegía a Garcilaso de la Vega en su muerte», de C. Mosquera de Figueroa, o la Ég. «Nemoroso», de Sá de Miranda. Iglesias Feijoo (p. 72) explica la adopción aquí del nombre garcilasiano como uso incidental entre los nombres de la Eg. I; pero nombrar a un personaje real es algo bastante más serio, y más aún en una elegia, que la simple adjudicación arbitraria del nombre a un ser de ficción: la persona es el nombre, y las semejanzas entre Garcilaso y su personaje fueron claramente advertidas por el poeta portugués.

${ }^{68}$ Así en la evocación de la amada a través de la contemplación de alguna prenda suya:

¡Oh dulces prendas por mi mal halladas, dulces y alegres cuando Dios quería, juntas estáis en la memoria mía y con ella en mi muerte conjuradas! ¿Quién me dijera, cuando las pasadas horas qu'en tanto bien por vos me vía, que me habiades de ser en algún día con tan grave dolor representadas?

(Son. X, v. 1-8),

Tengo una parte aquí de tus cabellos, Elisa, envueltos en un blanco paño, 
Tras la envoltura pastoril el lector reconoce en el texto elementos próximos a la vida del autor, bien en los hechos, bien en los sentimientos; y ésta es la base del género autobiográfico ${ }^{69}$. Pero la manipulación de esa realidad por medio de la transformación bucólica es índice literario evidente,

que nunca de mi seno se m'apartan; descójolos, y de un dolor tamaño enternecer me siento que sobre ellos nunca mis ojos de llorar se hartan.

(Ég. I, v. 352-357),

en la queja por tan funesto suceso:

¡Oh hado secutivo en mis dolores, cómo sentí tus leyes rigurosas! Cortaste'l árbol con manos dañosas y esparciste por tierra fruta y flores.

(Son. XXV, v. 1-4),

¡Oh miserable hado!

¡Oh tela delicada, antes de tiempo dada

a los agudos filos de la muerte!

(Ég. I, v. 259-262),

o en el deseo de contemplación post morten:

hasta que aquella eterna noche escura me cierre aquestos ojos que te vieron, dejándome con otros que te vean.

(Son. XXV, v. 12-14),

tal es la tenebrosa

noche de tu partir en que he quedado

de sombra y de temor atormentado, hasta que muerte el tiempo determine que a ver el deseado

sol de tu clara vista m'encamine.

(Ég. I, v. 319-323).

${ }^{69}$ La explica así Romera Castillo; «En los relatos autobiográficos de ficción, el autor, ocultándose tras la máscara de sus personajes y utilizando diversas ténicas de discurso, se biografia a través de sus obras. Acotado en una circunferencia, el escritor da, fingidamente, vueltas a su vida y proporciona una visión del mundo - de su mundo- desde una óptica 
que nos hace ver que lo que en el poema se muestra es sólo una imagen del poeta proyectada en la ficción. El autor, entonces, diciéndolo con palabras de Francisco Ayala, «queda ficcionalizado dentro de la estructura imaginaria que él mismo ha producido, aun en el caso de que aparezca en ella ostentando los caracteres de la más comprobable identidad personal» ${ }^{70}$. La lectura del texto bucólico no ha de hacerse entonces en clave biográfica estricta, seguramente no pretendida por los poetas. Aunque como cauce idóneo para la expresión de sentimientos facilitó la comunicación del amor con gran libertad, dentro de los patrones espirituales y estéticos vigentes. Como tal lo empleó Garcilaso, y con él lo más granado del parnaso español del siglo Xvı, desde los tempranos seguidores Acuña y Cetina (amantes, como Silvano-Damón y Vandalio, de Silvia-Galatea y Dórida-Amarilida, respectivamente), hasta el emocionado panegirista (como Iolas) de la belleza de la condesa de Gelves (Leucotea, etc.), el divino Herrera, dolorido cantor (como Delfis) también de su muerte (ahora bajo el nombre de Amarilis); acompañados por una larga lista de primeras figuras de la época.

El hecho comprobado de que no pueda en principio equipararse a algunos poetas con los personajes (o al sujeto lírico) de sus obras - pensamos, por ejemplo, en Ramírez Pagan - no anula esa disponibilidad alegórica que atribuimos con carácter general al poema bucólico ${ }^{71}$. Sabido es que "una experiencia imaginada por un poeta no es menos "cierta" y "sincera" que una "real"", como bien observa A. A. Parker". Al identificarse con los sentimientos que ahora recrea, su obra tiene ya toda la verdad poética que precisa.

personal, para que el lector -con quien ha establecido un pacto más o menos explícitopueda llegar a revivir las vivencias expuestas en unas coordenadas muy sui generis históricopersonales y a identificar, sin miedo a errar mucho, las huellas dactilares dejadas en la escritura por el manipulador de la misma" (op. cit., p. 39).

${ }_{70}$ La estructura narrativa y otras experiencias narrativas, Barcelona, Crítica, 1984, p. 21.

"De esta falta de concordancia se burla Castillejo en sus "Obras de conversación y pasatiempo", en unas coplas "Contra los encarecimientos de las coplas españolas que tratan de amores'»: "Y algunos hay, yo lo sé / que hacen obras fundadas / de coplas enamoradas, / sin tener causa por qué. / [...]» (v. 73-76, Obras, ed. de J. Domínguez Bordona, Madrid, Clásicos Castellanos, 1926, 3 vols.). También don Quijote alude a esta circunstancia, como justificación de su amor por Dulcinea: «[...] se las fingen, por dar subjeto a sus versos [...]» (I, cap. XXV).

La frase «fingen los poetas», empleada con frecuencia por los comentaristas y moralistas de la época, expresa un reproche tradicional que estaba ya en la República de Platón. La distinción aristotélica entre verdad histórica y verdad poética salvó a los poetas de la acusación de falsificadores; y en ella pusieron el acento todos los preceptistas del Renacimiento. El único tipo de realismo exigible en el poema, en cualquier poema, es, dice Bousoño, el que dé la ilusión de comunicar un contenido anímico tal como es, en su individualidad; le basta con su verdad interna (cfr. Teoria de la expresión poética, Madrid, Gredos, 1970, 5." ed., 2 vols., II, pp. 70 y 100-104).

${ }_{2}$ La filosofia del amor en la literatura española (1480-1680), Madrid, Cátedra, 1986, p.22. 